\title{
Nivelar la lengua, consolidar un mercado: Amado Alonso y la "época de oro" de la edición en Argentina
}

Leveling language, consolidating a market: Amado Alonso and the "golden age" of the publishing industry in Argentina

\author{
Laura Sesnich \\ Instituto de Investigaciones en Humanidades y Ciencias Sociales, Facultad de Humanidades y Ciencias de \\ la Educación Universidad Nacional de La Plata /CONICET, Argentina
}

\section{Resumen:}

Hacia fines de la década de 1930 la industria editorial argentina asistió a un proceso de apertura y de impulso internacional que suele vincularse a la crisis del libro español como resultado de la guerra civil, por el cual Buenos Aires pasó a convertirse en el principal centro editorial en habla hispana. Como muchos otros intelectuales españoles, Amado Alonso participó de ese proceso de auge editorial, no solo como miembro del grupo fundador de Losada y director de varias de sus colecciones, sino también mediante su producción ensayística, como dan cuenta sus artículos periodísticos publicados en La Nación en agosto de 1940, en donde Alonso reflexiona sobre el fenómeno editorial argentino y sus alcances, sobre todo en relación al potencial de la industria editora como agente unificador del idioma como consecuencia de la creciente difusión de libros argentinos por todo el continente americano. El objetivo de este trabajo es realizar un análisis de estos artículos de Amado Alonso, haciendo hincapié en aquellos aspectos en los cuales su propuesta de regulación lingüística para el mercado editorial en lengua española empalma con el factor económico, en tanto no deja de estar ceñida a la idea de una lengua unificada que pudiera facilitar y consolidar el comercio librero entre la Argentina y el resto de las naciones de habla hispana.

Palabras clave: Mercado editorial, Unidad del español, Hispanoamérica, Amado Alonso, siglo XX.

\section{Abstract:}

By the end of the 1930s, the Argentine publishing industry witnessed a process of international openness and momentum that is usually linked to the Spanish book crisis as a result of the Spanish Civil War, for which Buenos Aires became the main Spanishspeaking editorial center. Like many other Spanish intellectuals, Amado Alonso participated in this process of editorial growth, not only as a member of the founding group of the Losada publishing house and director of several of its collections, but also through his essay production as, for example, the series of three articles published in newspaper La Nación during August of 1940, where Alonso reflects on the Argentine publishing phenomenon and its scopes, especially in relation to the potential of the publishing industry as unifying agent of the language as a consequence of the increasing diffusion of Argentine books throughout the American continent. The aim of this paper is to analyze these articles by Amado Alonso, emphasizing those aspects in which his proposal of linguistic regulation for the Spanish-language publishing market links up with the economic factor, while still being close to the idea of a unified language that could facilitate and consolidate the bookseller trade between Argentina and the rest of the Spanish-speaking nations.

KEYWORDS: Publishing market, Unity of Spanish language, Latin America, Amado Alonso, 20th century.

\section{El nuevo contexto editorial argentino hacia fines de la década de 1930: LA EDITORIAL Losada y La PARTiCipación de Amado Alonso}

A pesar de lo relativamente tardío de la industrialización de España con respecto a la de otros países europeos, hacia 1920 su industria editorial asiste a una etapa de progresiva internacionalización que la lleva a convertirse en el principal centro exportador de libros a América Latina (Larraz, 2010). Sin embargo, esta situación cambia radicalmente hacia fines de la década de 1930, cuando el inicio de la Guerra Civil Española "genera un éxodo de editores y casas editoriales a América Latina, en especial México y Argentina” (de Diego, 2014: 97), que conduce a un proceso de apertura y de impulso internacional de la industria editorial en América Latina por el cual Buenos Aires pasó a convertirse en el principal centro editorial en habla hispana. ${ }^{1}$ 
Una de las editoriales que surgieron en ese momento y que fueron decisivas en lo que se conoce como "la época de oro" de la industria editorial argentina es Losada, fundada por el español Gonzalo Losada en agosto de 1938. Como muchos otros intelectuales españoles, el filólogo, lingüista y crítico literario Amado Alonso (quien no puede considerarse exiliado ya que se encontraba en Buenos Aires desde 1927, mucho antes del estallido de la Guerra Civil en España) participó de ese proceso de auge editorial, desempañándose en Losada como director de las colecciones "Estudios Literarios", "Filosofía y Teoría del Lenguaje" y "Colección de Textos Literarios" y como colaborador en la selección de títulos para la colección "Poetas de España y América" dirigida por Guillermo de Torre. Esta labor de Alonso es recordada por la editorial en su vigésimo aniversario:

Junto al influjo de su personalidad en la cátedra universitaria, en el Instituto de Filología, en los cursillos y conferencias de entidades privadas, debemos citar su asociación a la empresa de difusión del libro, al colaborar como director fundador en la editorial Losada desde los primeros días. Ella puede vanagloriarse -haciendo ahora un balance de las actividades cumplidas durante veinte años- de haber tenido en el campo de la lingüística y de la crítica literaria a una figura de la talla de Amado Alonso. (Barrenechea, 1958: 23)

Esta presencia de Alonso en diversos frentes de la cultura como la academia, en entidades privadas y en el mercado del libro, habla de un contexto particular en el que la labor del lingüista podía ser requerida en ámbitos por fuera del estrictamente universitario. ${ }^{2}$ Sin embargo, debe tenerse en cuenta otro tipo de participación de intelectuales como Amado Alonso en el proceso de auge de la industria editorial argentina, tal como señala Alejandrina Falcón: "los intelectuales colaboraron con este proceso, no solo como directores de colección, traductores o correctores, sino específicamente apuntalándolo con su producción ensayística" (2010a: 1). Es el caso de Alonso, cuya contribución ensayística más importante en relación con la industria editorial es la serie de tres artículos aparecidos originalmente en el suplemento literario del diario La Nación durante el mes de agosto de 1940 y publicados tres años más tarde como libro por la Institución Cultural Española bajo el título La Argentina y la nivelación del idioma. En ellos el filólogo reflexiona sobre el fenómeno editorial argentino y sus alcances, sobre todo en relación con el potencial de la industria editora en tanto agente unificador del idioma como consecuencia de la creciente difusión de libros argentinos por todo el continente americano. El objetivo de este trabajo es realizar un análisis de estos artículos de Amado Alonso, haciendo hincapié en aquellos aspectos en los cuales su propuesta de regulación lingüística para el mercado editorial en lengua española empalma con el factor económico, en tanto no deja de estar ceñida a la idea de una lengua unificada que pudiera facilitar y consolidar el comercio librero entre la Argentina y el resto de las naciones de habla hispana.

\section{La Argentina y la NiVelación Del idioma: un programa Para la lengua de los LIBROS}

Los artículos a los que hacemos referencia se titulan "La Argentina en la dirección inmediata del idioma" (publicado el 4 de agosto de 1940), "De cómo se cumplirá el influjo argentino en la lengua general" (11 de agosto) y "Las Academias y la unificación del idioma" (18 de agosto), y en ellos Alonso insiste con ciertas ideas acerca de la legua literaria y la uniformidad de la lengua española que ya había venido desarrollando a lo largo de la década de 1930. La tesis principal en estos artículos es que "si la lengua literaria es el más eficaz agente nivelador, ahora es cuando América empieza a ser parte activa en el mantenimiento de la unidad del idioma" (1944: 406, cursivas nuestras). Con "agente nivelador" se refiere a la capacidad de la lengua literaria (de cierta lengua literaria, sin duda) de funcionar como modelo de una variedad de lengua que Alonso llama "lengua común” "lengua culta general” y que pueden identificarse con el concepto de "lengua legítima” de Pierre Bourdieu. ${ }^{3}$ Con "ahora”, Alonso se refiere a la radical transformación del mercado editorial en habla hispana que, como ya se ha mencionado, a partir de la segunda mitad de la década de 1930 
traslada su centro de producción de la España en guerra a Latinoamérica, principalmente a Buenos Aires y México: "Buenos Aires se ha convertido en el mayor centro editorial de habla española, y México le sigue en importancia" (Alonso 1940a: 1).

Proponemos, a modo de hipótesis de lectura de estos textos, dos cuestiones. Una, que este conjunto de ideas que Alonso venía desde hace tiempo desarrollando en torno a la unidad del idioma encuentra un vehículo factible de realización en la floreciente industria editorial argentina. Por otro lado, que esta floreciente industria editorial argentina (a la que Alonso no era ajeno, dada su participación en Losada) le brinda un nuevo argumento a favor de la uniformidad de la lengua española: el económico. Es decir que, en esta propuesta de Alonso, lengua y mercado se necesitan y benefician recíprocamente.

\section{1 "La Argentina en la dirección inmediata del idioma": Buenos Aires y la nueva situación del mercado editorial en habla hispana.}

En este primer artículo de la serie, Amado Alonso insiste en la necesaria unidad de la lengua por la que ya había abogado en textos anteriores como "El problema argentino de la lengua", aparecido en Sur en 1932 e incluido más tarde en su libro El problema de la lengua en América de 1935, en donde afirmara que "un idioma nacional literario, independiente del castellano general, sería un contrasentido, no solo por motivos prácticos de conveniencia, sino por razones teóricas y de conocimiento" (1935: 44, cursivas en el original). Transcurridos varios años desde esas primeras reflexiones, Alonso vuelve a insistir sobre la conveniencia de una lengua unificada, una "lengua común como instrumento social de intercomunicación" (1935: 55), apelando ahora a nuevos argumentos: "con una lengua diferente, los españoles y los americanos de las otras naciones no nos entenderían, ni nosotros a ellos. Lo que necesita la prosperidad y grandeza de una nación es una lengua de largo alcance, tanto para las ciencias y las artes como para el comercio" (1943:21). La unidad que antes el lingüista justificaba "por razones teóricas y de conocimiento", encuentra una nueva fundamentación en la prosperidad asociada al comercio, que a viene a estar representado, como resulta evidente a lo largo de sus afirmaciones, por la industria editorial. De este modo, el argumento económico viene a sostener la idea de una lengua común entendida como moneda común dentro del mercado de libros.

Por otro lado, es también evidente, según Alonso, que esta lengua no podría llegar ser “común”, es decir, generalizarse, más que a través de los libros que la vehiculizan:

El lenguaje hablado de Castilla no influye en la unificación de un idioma extendido por veinte países más que a través de los libros: por lo que de él recoge la lengua literaria. El agente unificador es la lengua literaria, no la oral de una ciudad ni de una región. (1940a)

Serían los libros entonces, el necesario elemento de propagación de la variedad de lengua que postula Alonso y, en este contexto, se comprende la importancia que para ello tiene Buenos Aires, en tanto principal centro editorial del período y por tanto nuevo principal foco irradiador de lengua legítima.

Este nuevo lugar de preeminencia que tiene Buenos Aires en la producción de libros para el resto de los países de habla española y, por ende, en la difusión de esta variedad de lengua literaria, es un punto central en la propuesta de nivelación lingüística de Alonso de un modo que no había figurado en textos anteriores a este despegue editorial, como se desprende del cotejo entre sus textos previos y posteriores a este hecho. Sirva como ejemplo el caso de un artículo que Alonso publica en La Nación en agosto de 1933, es decir, exactamente siete años antes de los artículos sobre la materia incluidos en La Argentina y la nivelación del idioma y que lleva por título "Balance de una Exposición". En esta nota el lingüista vuelca sus comentarios acerca de la Exposición del Libro Español que se llevó a cabo entre el 24 de julio y el 18 de agosto de ese año y de la que actuó como Secretario. Alonso define esta exposición como "el acto más importante de una intensa campaña -cultural y económica- en pro del libro castellano”, y también afirma que 
A todos nos conviene una mayor difusión del libro americano fuera de su país productor, por el resto de América y por España. Ahora bien, en esa tarea los argentinos deben tomar una actitud activa. ¿Van a confiar todo a la labor ajena? Por el momento, parece que es España el país más a propósito para comenzar esa campaña difusora de la producción intelectual argentina. (1933b: 6)

Siete años después, esa campaña difusora de la producción argentina no solo parece haber comenzado sino que lo ha hecho desde Buenos Aires (y no desde España, como se figuraba Alonso) y es al momento la más importante en habla hispana: "la Argentina se ha hecho poderosa en la industria ligera; en la producción de esos libros que corren por muchas manos y que se renuevan y reemplazan incesantemente. Y ésos son los libros que, principalmente, recogen y expanden el sentido de una lengua unificada" (1940a, cursivas en el original). Consecuentemente, son esos libros de industria ligera, "que corren por muchas manos", los que Alonso, desde su participación en Losada, se propone difundir:

\begin{abstract}
La Losada va cobrando mucha importancia. Ahora he organizado una colección de tomitos de unas 150 páginas (o poco más) que se titularán "Vida y Obra de...”. [...] Son libros destinados a profesores secundarios, alumnos universitarios, periodistas y escritores, etc. [...] Una visión sintética, pues. Al final, un par de páginas con la bibliografía esencial, haciendo en cada título alguna indicación útil (qué va a encontrar en esa obra el lector). Queremos hacer tomitos baratos, para vender muchos, y por eso proponemos pagarles a los autores el 10\%. De ofrecer el 15\% tendríamos que subir el precio unos centavos más, lo cual perjudicaría a la venta. (Carta de Amado Alonso a Alfonso Reyes, 1939; en Venier, 2008: 103-104)
\end{abstract}

\title{
2.2. "De cómo se cumplirá el influjo argentino en la lengua general": la teoría de la acomodación.
}

En esta segunda entrega, Alonso expone los argumentos más propiamente lingüísticos de su teoría sobre la lengua de los libros. Para ello parte de afirmaciones que ya había volcado anteriormente en "El porvenir de nuestra lengua", artículo aparecido en la revista Sur en 1933, en donde afirma, principalmente, el carácter modélico de la lengua literaria y el influjo de esta respecto de la lengua urbana. Menciona además los conceptos de nivelación y unificación y recién hacia final del artículo hace una pequeña mención al intercambio de libros y de prensa periódica, definiéndolo como "una constante invitación recíproca, entre la Argentina y las demás repúblicas hispánicas, a mantener en continuidad un mismo ideal de lengua" (1933a: 150). Años más tarde, el comercio de libros no será considerado un aspecto más de la cuestión sino la herramienta clave para lograr este mejoramiento lingüístico, a la vez que un nuevo motivo para dicho mejoramiento.

Por otro lado, ese mejoramiento resultaba urgente en la Buenos Aires devenida en principal centro editorial, en tanto que la lengua oral que allí se hablaba no tenía para Alonso suficiente calidad, como venía ya señalando desde hacía varios años:

En esta ciudad de aluvión, la lengua que más se oye, no en los bajos fondos ni en personas de cultura excepcional, sino entre la mayoría de los profesionales, de los empleados, de los comerciantes y de sus familias, y hasta en profesores, es de una calidad demasiado baja y de una cantidad de elementos demasiado pobre. En el obligado injerto de la lengua escrita en la oral, la hablada por la masa de los porteños no está en condiciones de colaborar con dignidad en la literaria. (1935: 62)

Es comprensible entonces que para Alonso este problema tome otros contornos (y otra gravedad) cuando Buenos Aires se transforma en centro productor y exportador de libros en lengua española:

El libro argentino no sabía antes salir de su casa; ahora se halla presidiendo los escaparates de las librerías de toda América. ¡Qué formidable instrumento de irradiación argentina! ¡Y qué grandes deberes para con el resto de América nos revela ese poder! (1940a)

Su teoría parte de la premisa de que el español de América es una lengua extendida a través de un territorio muy vasto aunque mal comunicado, en el que la lengua de los escritores es el modelo de lengua que se toma por legítima en los sectores cultos y los sistemas educativos de cada país. De este modo, a medida que los escritores van introduciendo diversas formas o modismos, estas se van propagando y consolidando al ser adoptadas en 
el hablar de los sectores ilustrados y al ser introducidas en las escuelas. Es por este proceso que los escritores son, para Alonso, un eslabón clave en el proceso de unificación de la lengua legítima, y desde allí se entiende su crítica al tipo de escritor "defectuoso" e "inhábil" que en 1935 había definido como "el escritor-masa":

Ese escritor-masa es no solo el poeta mediocre y el oscuro cuentista y el periodista anónimo, sino también el médico que publica su monografía y el abogado sus panfletos y el político sus manifiestos. Y no se me diga que mi rebusca es ociosa, ya que entre los escritores solo cuentan los de personalidad; precisamente nos interesan los otros como elemento atmosférico en el que viven sumergidos los verdaderos escritores. (1935: 49)

Entonces, partiendo de esta premisa acerca de la lengua literaria, Alonso analiza el nuevo contexto americano respecto de la edición de libros de acuerdo a dos puntos:

$\left.1^{\circ}\right)$ La lengua de los libros es la que sostiene a la lengua hablada general; pero los libros de cada república americana, con escasas excepciones, solo se han leído hasta ahora en sus respectivos países, y por eso (salvo algún caso aislado) no han influido en la lengua general más que como agentes propagadores. Solo los libros de España llegaban a todas partes.

$\left.2^{\circ}\right)$ [...] Hasta ahora, los escritores que han influido activamente en la unificación de la lengua general, en su inmensa mayoría españoles, no incluían, en su obligatoria acomodación la presencia del gusto lingüístico americano. En lo que tocaba al lenguaje, escribían sus libros para España, aunque unos cientos de ejemplares se vendieran por América. (1940b)

El radical cambio experimentado por esos años respecto de la producción y distribución de libros en habla hispana hizo que los libros argentinos, y en menor medida los mexicanos, lleguen a todas partes de América al punto que ser "casi los únicos que circulan" (1940b). Esta nueva situación editorial trajo consigo un hecho de máxima importancia según Alonso:

La acomodación de los escritores y traductores peninsulares a los gustos y a los usos americanos, y especialmente a los argentinos. La acomodación de más bulto es esa que podríamos llamar el temor a chocar: la que hace evitar las formas peninsulares que en América no circulan. Pero esta acomodación de signo negativo supone otra positiva: la que, en el instante de la elección, hace al escritor preferir las formas y modos peninsulares de expresión que coinciden con las americanas y preferirlas porque aquí son vigentes. Luego sigue el dar entrada a formas y modos americanos que en España suenan a arcaicos o a regionales (frazada, canilla, por ejemplo), y hacerlos entrar con valor de vigencia normal, sin intención arcaizante ni regionalista. Todo esto representa como si dijéramos el programa mínimo de acomodación americana de los escritores y traductores españoles que publican libros en las editoriales argentinas. (1940b)

El nuevo panorama editorial funciona en forma positiva para la lengua como sistema de difusión y homogenización de la variedad de lengua culta que Alonso considera lengua literaria, a la vez que una lengua literaria desprovista de localismos y llevada a un cierto nivel de uniformidad funciona también de forma positiva para el mercado editorial, al favorecer la difusión de libros argentinos por todos los países hispanohablantes, es decir, al funcionar como "moneda lingüística de circulación general” (1940b). Claro que para ello, la lengua literaria de los escritores de Buenos Aires debía ser ahora de una "calidad” satisfactoria (no como la de los "escritores-masa") y a eso se refería Alonso cuando decía aquello de los "deberes para con el resto de América" que debía tener en cuenta Buenos Aires a través de este "formidable instrumento de irradiación argentina" que significaba su pujante industria editorial. Como ya dijimos, en la propuesta de Alonso, lengua y mercado se necesitan y benefician recíprocamente.

\section{3. "Las Academias y la unificación del idioma": Mercado y Academia en la disputa por el "timón de la lengua".}

En este tercer y último artículo de la serie, Alonso explora la cuestión de las academias del idioma y las voces y modismos particulares de la variedad del español hablado en Argentina. En este punto, Alonso propone una posible objeción a su teoría sobre la acomodación respecto de cuál sería el rol de la Academia Española en este proceso, siendo que aunque la floreciente industria editora argentina haga circular por los países hispanohablantes "las modalidades de nuestro buen castellano", no deja de ser la Academia Española 
quien tiene el "timón de la lengua" en estos asuntos (1940c). Alonso se explaya sobre este punto diciendo que

El medio donde la Academia aplica sus aparatos registradores es, otra vez, la lengua escrita. Las palabras y maneras de decir que adquieren carta de naturaleza en los buenos libros, ésas son las que la Academia recoge después como correctas. Luego si la Argentina impone sus libros en todas partes, libres de la limitación regional, y si con el intercambio y con las ventajas materiales de sus grandes casas editoriales influye en el lenguaje de los otros escritores, la Academia Española irá anotando en sus libros estos aportes argentinos. (1940c)

A este pronóstico de signo optimista Alonso sumará una propuesta de trabajo lexicográfico a realizar por la recientemente fundada Academia Argentina de Letras, tendiente a recoger y categorizar los argentinismos en circulación a los fines de su incorporación en los diccionarios y demás instrumentos lingüísticos de la Academia Española, asegurando que

Un trabajo así haría que la segura influencia que gracias al poder expansivo de su industria editorial va a tener la Argentina desde ahora en la lengua general, fuera aún mucho más cuantiosa y de mayor radio de expansión y, sobre todo, aseguraría su calidad, que es lo que más puede ambicionar una Argentina que añada a la justa ambición de honra el más severo sentido de la responsabilidad. (1940c)

\section{Algunas RefleXiones finales}

A lo largo de estos capítulos de La Argentina y la nivelación del idioma hay ciertas ideas que persisten. En principio, en estos y en textos anteriores de Alonso existe un claro y explícito posicionamiento en contra de la independencia idiomática. Ya en 1935 Alonso afirmaba que "variedad no es escisión" (1935: 57), y esta idea prevalece, bajo otras formas y renovados argumentos, en sus textos más explícitamente relacionados con la cuestión del mercado editorial. Si bien Alonso admite (no puede no hacerlo, por otra parte) que el foco de irradiación del libro en lengua española al resto del mundo hispanohablante se ha trasladado a Buenos Aires, sus afirmaciones sugieren que lo que no se habría trasladado es la supuesta condición de Madrid de centro ("meridiano", por decirlo en términos de la conocida polémica) cultural e idiomático. An sumida en las secuelas de la Guerra Civil, la condición de España de primus inter pares no está en disputa para Alonso: "Sería desastroso para la calidad de nuestra lengua la eliminación de España en su gobierno. [...] la continuación de España en la dirección del idioma comn no es solo históricamente justa, sino prácticamente necesaria" (1940a). En este punto, la propuesta de Alonso podría leerse como un nuevo capítulo de la polémica del meridiano intelectual, suscitada en el mismo año en que el filólogo desembarca en Buenos Aires y duramente criticada por los martinfierristas, teniendo en cuenta que, como afirma Falcón,

Esa polémica de carácter internacional enfrentó dos ideologías lingüísticas y dos políticas culturales vinculadas con inquietudes e intereses nacionales divergentes e históricamente situados: la captación del mercado lector americano por parte de España y la lucha por definir qué modelo de lengua legítima habría de regir las producciones literarias en Argentina. (2010b: 40$)^{4}$

Para los años en que Alonso escribió los artículos que nos ocupan, ese mercado lector americano que preocupaba a Guillermo de Torre había crecido en número y en importancia: "Se ha creado el lector americano, o por lo menos se ha creado la masa de lectores: el libro que contaba con doscientos o cuatrocientos compradores cuando venía de España tiene cinco mil o diez mil ahora que sale de prensas americanas" (Alonso, 1940a). Sin embargo, las afirmaciones de Alonso sobre España como sede de la producción literaria y del gobierno idiomático, llevan a preguntarse cuál sería entonces en su propuesta el lugar de Buenos Aires, "meridiano editorial" de la industria editorial argentina no es un "trueque" de Buenos Aires por Madrid "sino un cambio de régimen: en vez del centro único, ahora va a haber tres focos de regulación, recíprocamente influidos: Madrid, Buenos Aires y México" (1940a). Se desprende de este tipo de afirmaciones que, en la propuesta de Alonso, la 
España en guerra no cede su influjo, sino que lo presta, y en este contexto las industrias editoriales argentina y mexicana pueden aspirar a seguir formando parte de este de triple foco de regulación, que según Alonso continuará una vez que España se recupere de la guerra puesto que "se ha creado el lector americano, o por lo menos se ha creado la masa de lectores" (1940a). En este punto, la situación del lector americano habría cambiado desde 1933, cuando en "Balance de una Exposición" Alonso aseguraba:

Formamos entre todas las repúblicas de aquende y allende el mar cien millones de hispano-hablantes. ¿Cuántos de ellos somos hispano-leyentes? [...] El éxito verdadero de la Exposición será la conquista de ésos, de algunos de esos lectores acelerados del tranvía o del ómnibus, para la lectura casera y reposada del libro. Ganados algunos, hay que confiar en el saludable contagio. $(1933: 6)$

Otra idea recurrente en los textos de Alonso es la premisa de que la lengua literaria es modelo para la lengua general. Ya en "El porvenir de nuestra lengua" afirmaba:

Cuando aparecieron las lenguas literarias o, si se quiere, la forma literaria de las lenguas, esta aceleró en todas partes el proceso de reintegración, nivelación, unificación y elevación del lenguaje hablado, por ser para cada individuo, mediata o inmediatamente, el punto de referencia más seguro y más prestigioso posible. Desde entonces, el ideal de lengua que a cada uno mueve estuvo influido más o menos cercanamente por un mismo tipo, el literario; y el parentesco creciente de los ideales regionales, locales e individuales, nutridos en el mismo ideal de lengua literaria, ha hecho que las diferencias idiomáticas se vayan borrando. (Alonso, 1933: 146-147)

En tanto no es materia de debate y simplemente se da por válida, esta correspondencia entre lengua literaria y lenguaje hablado funciona en la propuesta de Alonso a modo de dogma. Pero, más aún, remite a una variedad de lengua literaria en particular visiblemente elitista, dado que responde a un modelo de norma que era "la lengua culta de las minorías letradas productoras de bienes culturales" (Falcón, 2010a: 6). En la propuesta de Alonso, la lengua de estos sectores letrados viene a representar la excelencia lingüística según la cual la lengua legítima establece su diferencia respecto de otras formas:

Las propiedades que caracterizan la excelencia lingüística pueden resumirse en dos palabras: distinción y corrección. El trabajo que se realiza en el campo literario produce las apariencias de una lengua original procediendo a un conjunto de derivaciones que tienen por principio una diferencia con relación a los usos más frecuentes, es decir, "comunes", "corrientes", "vulgares". (Bourdieu, 1999: 34)

Este tipo de lengua literaria uniforme y desprovista de particularidades locales, que se corresponde con el hablar de las minorías cultas de los grandes centros urbanos, era el punto central en las reflexiones de Alonso acerca de la uniformidad cultural de los países hispanohablantes. Luego de comenzado el proceso de auge editorial argentino será además necesaria en el "concierto universal de las ciencias, de las artes y del comercio" (1940a). Lengua y comercio, entonces, son condiciones necesarias en este nuevo contexto editorial. Sin embargo, el rechazo de ciertos entendidos en materia lingüística como Delfina Molina y Vedia ${ }^{6}$ a una posible conjunción de intereses lingüísticos e intereses comerciales da cuenta, por un lado, de que este era un tema en debate ya a mediados de la década de 1930, y por otro, que las posiciones al respecto estaban lejos de ser homogéneas:

A menudo se debate aquí y en España el asunto de la unificación de la lengua, el cual nunca pierde actualidad dada su naturaleza evidentemente importantísima.

Pero lo cierto es que so capa de interés mundial, filólogos, libreros, y periodistas de toda laya utilizan el tema para cubrir con manto espectable, intenciones mucho menos espectables, como ser logreríos, negocios editoriales, y aprovechadas picardías, de quienes solo persiguen el medro personal, importándoseles un ardite del bien público. (1936:65)

En definitiva, la propuesta de Amado Alonso postula una retroalimentación entre lengua literaria y mercado editorial en tanto este tipo de lengua literaria encontraría su vehículo de difusión por toda América Latina en la industria editorial, al tiempo que este crecimiento del mercado del libro en habla hispana requeriría, a su vez, según Alonso, de esta lengua literaria unificada para su ampliación y consolidación. 
Las cuestiones aquí expuestas dan cuenta, además, no solo de ciertos debates que suscitó la rápida transformación de Buenos Aires en el principal centro editorial en lengua española sino también de cómo parte de esos debates fueron asumidos por algunos representantes de las instituciones de la cultura (como Amado Alonso, director del Instituto de Filología de la Universidad de Buenos Aires) que ante la creciente emergencia de las industrias culturales ${ }^{8}$ comenzaron a preocuparse por establecer algún tipo de regulación acerca de la lengua contenida en estos productos culturales de circulación masiva, en consonancia con diversos intereses, ya sea ideológicos, políticos o económicos.

\section{ReFERENCIAS}

Adorno, T. y Horkheimer, M. (2006). La industria cultural. Ilustración como engaño de masas, Dialéctica de la Ilustración. Madrid: Trotta, 165-212.

Alonso, A. (1932). El problema argentino de la lengua, Sur, nº 6, 124-178.

Alonso, A. (1933a). El porvenir de nuestra lengua, Sur, $n^{\circ} 8,141-150$.

Alonso, A. (1933b). Balance de una exposición, La Nación, 25 de agosto de 1933, p. 6.

Alonso, A. (1935). El problema de la lengua en América. Madrid: Espasa-Calpe.

Alonso, A. (1940a). La Argentina en la dirección inmediata del idioma, La Nación, 4 de agosto, Artes/Letras-1.

Alonso, A. (1940b). De cómo se cumplirá el influjo argentino en la lengua general, La Nación, 11 de agosto, Artes/ Letras-2.

Alonso, A. (1940c). Las academias y la unificación del idioma, La Nación, 18 de agosto, Artes/Letras-4.

Alonso, A. (1943). La Argentina y la nivelación del idioma. Buenos Aires: Institución Cultural Española.

Alonso, A. (1944). Sobre: Ramón Menéndez Pidal, La unidad del idioma y Amado Alonso, La Argentina y la nivelación del idioma, Revista de Filología Hispánica, VI, nº 4, 402-409.

Arnoux, E. y Bein, R. (1995). La valoración de Amado Alonso de la variedad rioplatense del español, Cauce, n 18-19, 183-194.

Barrenechea, A. M. (1958). Amado Alonso, Negro sobre blanco, nº 8, número extraordinario: "Vigésimo aniversario de la editorial Losada", noviembre, 23.

Bourdieu, P. (1999). ¿Qué significa hablar? Economia de los intercambios lingüisticos. Madrid: Akal.

Bourdieu, P. (2007). Una revolución conservadora en la edición, Intelectuales, politicaypoder. Buenos Aires: EUDEBA, pp. 223-267.

de Diego, J. L. (dir.) (2014). Editores y politicas editoriales en Argentina (1880-2010). Buenos Aires: FCE.

de Diego, J. L. (2015). La otra cara de Jano. Una mirada crítica sobre el libro y la edición. Buenos Aires: Ampersand.

Editorial Losada (2010). La editorial Losada, una historia abierta desde 1938. Buenos Aires: Losada.

Ennis, J. A. (2008). Decir la lengua. Debates ideológico-lingüisticos en Argentina desde 1837. Frankfurt et al.: Peter Lang.

Esposito, F. (2010). Los editores españoles en la Argentina (1892-1938). En C. Altamirano (dir.), Historia de los intelectuales en América Latina II. Los avatares de la "ciudad letrada" en el siglo XX. Buenos Aires: Katz.

Falcón, A. (2010a). 'Un español sin patria ninguna': el idioma de los libros en tiempos de auge editorial, Actas del IX Congreso Argentino de Hispanistas, La Plata.

Falcón, A. (2010b). El idioma de los libros: antecedentes y proyecciones de la polémica "Madrid, meridiano 'editorial' de Hispanoamérica", Iberoamericana, X, 37, 39-58.

Larraz, F. (2010). Una historia transatlántica del libro. Relaciones editoriales entre España y América Latina (1936-1950). Guijón: Trea.

Lida, M. (2012). Una lengua nacional aluvial para la Argentina. Jorge Luis Borges, Américo Castro y Amado Alonso en torno al idioma de los argentinos, Prismas, no 16, 99-119. 
Manzoni, C. (1996). La polémica del meridiano intelectual, Estudios. Revista de Investigaciones Literarias, IV, 7 , 121-132.

Molina y Vedia de Bastianini, D. (1936). Cuestiones Lingüisticas de América. Buenos Aires: Librería del Colegio.

Palomo Olmos, B. (1997-1998). Amado Alonso: Bibliografía comentada, Cauce, no 20-21, 183-232.

Toscano y García, G. (2009). Materiales para una historia del Instituto de Filología de la UBA (1920-1926), RILI, I (13), 113-135.

Toscano y García, G. (2013). Language debates and the institutionalization of philology in Argentina in the first half of the twentieth century. En J. Del Valle (dir.), A political history of Spanish. The Making of a Language. Cambridge: CUP.

Toscano y García, G. (2015). 'Antes que mentir exclusividad que no siento'. Saberes lingüísticos e instituciones reguladoras en Delfina Molina y Vedia, Estudios de Lingüistica del Español, 36 (2015), 25-56.

Venier, M. E. (ed.) (2008). Crónica parcial. Cartas de Alfonso Reyes y Amado Alonso. México: Colegio de México.

\section{Notas}

1 Si bien suele señalarse este acontecimiento como la causa del inicio del despegue de la industria editorial argentina, no deben dejar de tenerse en cuenta otros factores que prepararon el terreno para esta expansión, tal como señala Fabio Esposito: "La Guerra Civil Española [...] no fue el único factor que determinó la instalación de numerosos editores españoles en Buenos Aires y el consecuente despegue de esa industria en la Argentina. Si bien este acontecimiento histórico tuvo gran impacto sobre ese sector, la expansión de las editoriales españolas en Hispanoamérica y en particular en la Argentina ya poseía una dimensión considerable antes de la Guerra Civil. De manera que los editores del exilio republicano no debieron recorrer un camino inexplorado, sino que pudieron sostener sus emprendimientos en un complejo marco de relaciones institucionales, comerciales, culturales y políticas que se habían ido tejiendo tenazmente desde fines del siglo XIX" (2010: 519).

2 Tal como afirma Miranda Lida, "el universo de intervención del lingüista profesional no se circunscribía al claustro universitario, sino que se extendía a la totalidad de la cultura de masas, en su más extensa y cabal expresión. Todas las industrias culturales argentinas, y en especial las de exportación, podían ser objeto de intervención por parte de los lingüistas del Instituto de Filología [...]. La intervención del lingüista era de primera importancia, puesto que se encargaría de velar por el buen uso del lenguaje en las industrias culturales" (2012: 114).

3 Respecto de este término, Bourdieu afirma: "Hablar de la lengua, sin ninguna otra precisión, como hacen los lingüistas, es aceptar tácitamente la definición oficial de la lengua oficial de una unidad política: la lengua que, en los límites territoriales de esa unidad, se impone a todos los súbditos como la única legítima, tanto más imperativamente cuanto más oficial es la circunstancia [...]. Producida por autores que tienen autoridad para describir, fijada y codificada por los gramáticos y profesores, encargados también de inculcar su dominio, la lengua es un código, entendido no solo como cifra que permite establecer equivalencias entre sonidos y sentidos, sino también como un sistema de normas que regulan las prácticas lingüísticas" (1999: 19, cursivas en el original).

4 En su análisis de la polémica de 1927, Alejandrina Falcón asigna un lugar central a la circulación de bienes culturales entre España y la América hispanohablante en tanto plantea que relación entre el problema del libro y el tema de la lengua fue la motivación implícita de la polémica: "En un editorial publicado en abril de 1928 y titulado 'Preliminares. Ante la exposición del libro argentino-uruguayo en Madrid', Guillermo de Torre devela la incógnita de la famosa polémica o, cuando menos, cancela toda duda: 'Una de las consecuencias empíricas que cierto día -en el curso de una interviú- me permití extraer de las múltiples lecciones brindadas por la clamorosa cuestión del 'meridiano intelectual' fue la siguiente: en el fondo -afirmé- todo este pleito inevitable y salutífero entrañaba más bien un problema editorial y librero que una cuestión literaria"” (Falcón, 2010b: 50).

5 Con ese término se refería en 1941 Rafael Salazar, presidente de la Cámara Argentina del Libro, a la capital argentina: "Buenos Aires se ha transformado en los últimos tiempos en el meridiano editorial de los países de habla española. El crecimiento logrado en este sentido es verdaderamente extraordinario" (Biblos $\mathrm{n}^{\circ}$ 1, p. 11, citado en Larraz 2007: 84-85).

6 Delfina Molina y Vedia de Bastianini (1879-1961) fue una escritora argentina, esposa de René Bastianini, un gramático escolar muy reconocido en las primeras décadas del siglo XX. Fundó en 1935 la SADEL (Sociedad Argentina de Estudios Lingüísticos), institución que presidió entre 1935 y 1937. Fue también autora de varios libros, entre ellos el ensayo de 1936 Cuestiones Lingüisticas de América (ver Toscano y García 2015).

7 No podemos afirmar a ciencia cierta a cuáles "filólogos, libreros y periodistas de toda laya" se refería Delfina Molina y Vedia, aunque sí tenemos noticia de textos como Babel y el castellano (1928) de Arturo Capdevila, de gran circulación 
desde fines de la década de 1920, que abordó cuestiones como la unidad idiomática hispanohablante y la circulación de bienes culturales entre España y América, temas que serían de interés para la industria editorial argentina. Como afirma Falcón: "Sus dichos se insertan en una red de discursos y prácticas que favorecieron la cohesión de un cuerpo de ideas sobre la norma al uso en el medio editorial argentino hasta la primera mitad del siglo XX. Prueba de ello es que, durante el auge editorial, Capdevila tuvo un lugar destacado en el catálogo de Losada" (2010a:2). Se espera que en futuros trabajos podamos profundizar en esta cuestión.

8 Hablamos de industrias culturales en general, y no únicamente de la industria editorial, porque consideramos que es durante la década de 1930 que se produce el proceso de expansión de las industrias culturales argentinas que lleva a un punto de inflexión en los debates sobre la lengua por parte de los sectores ilustrados. Estos debates se dieron respecto de la lengua de la industria editorial, pero también de la lengua de la radio, el cine y otros productos culturales. Sin ir más lejos, el mismo Alonso, en La Argentina y la nivelación del idioma, incluye su artículo "El periodismo, la radio y el cinematógrafo", publicado originalmente en la revista Saber Vivir en noviembre de 1942, en el cual se manifiesta acerca de la lengua de estas manifestaciones culturales. 